\title{
This role is also that of Science
}

\author{
António José Silva*
}

It may seem redundant to address Sport as a development trigger but, sometimes, redundancy is necessary for someone to be heard.

The commanding voices of Philosophy in the $\mathrm{XX}^{\text {th }}$ century take sciences as trivial, by expressing the notion that Science has nothing to do with the ontological and metaphysical statutes of men.

What is at stake is too much important, as the attack is not aimed at Sciences, organizations and institutions, nor at the people, but rather against Reason itself.

We found ourselves immersed in irrationalities and superstitions in the most primitive form of belief. Worldwide there are three times more astrologists than there are physics. In Portugal, also in Sport, there are numberless stand-coaches and pseudo-writers, which all speak and write about exercise and appear as public opinion makers, stating banalities that discredit Sport and its professionals.

In western science, what is axiomatic is not merely the concept of progress, but rather the concept of constant and unlimited progress. And we take for granted this lack of limits... Indeed, it seems ...... In fact, it is a deeply enigmatic assumption, taking into account the metaphysical meaning of the term.

And it is from these assumptions that we must analyse the role of Sport and Exercise. Biological life may be increased in duration, but death will come: and the challenge is therefore the quality of an extended life. In Sport and exercise, progress has more than a technical relevance, it has an ontological relevance: the enhancement of a life cycle.

Sport is, therefore, an immeasurable asset and holds opportunity to induce peace and be a promoter of several social causes.

Sport is one of the possible, perhaps the main, cultural objectification and historical form of movement. This is only possible by valuing the fundamental character of the body in motion, because it is upon it that the sports body is installed and merges. Even giving it a fundamental meaning, it has not yet found its value due to the failure in the evaluation of its return, whether educational, social, health, economic or structural.

The importance of Sport and its institutions cannot be measured, as much as some state so, by performance indicators in an international setting (this leads to unfair, unproportioned comparisons among sports with different density and international coverage).

A message that, unfortunately, has passed to general society, involving risks to lower even more the national sport involvement is: resources must be mainly focused in the few sports with international merit. With time, this will end up in an overall failure of national Sport, and subsequently a progressive underfinancing of the Sport will appear.

Every organization that deal with Sport cannot deviate from what is its main mission, to organize, promote and spread the Sport for a permanent and constant demonstration that what is done and how it's done fully respect the high public interest and, ultimately, serves the people.

This role is also that of Science.

\footnotetext{
"University of Trás-os-Montes And Alto Douro, Vila Real, Portugal; Research Centre in Sports Sciences, Health Sciences and Human Development, CIDESD, Portugal; Portuguese Swimming Federation Complexo Desportivo da UTAD, Quinta de Prados, 5000 Vila Real, Portugal.E-mail: ajsilva@utad.pt
} 